Contributors of manuscripts who closely adhere to the following guidelines will receive prompt and efficient consideration.

IMPORTANT: Please see http://www.agecon.uga.edu/ jaae/guidelines.htm for a detailed description of the following submission guidelines:

1. Copyright. The $J A A E$ is copyrighted. Authors will be required to sign a release form, when manuscripts are accepted, which will prohibit publication of material contained in the article elsewhere unless specific permission is granted by the editor(s).

2. Publication Costs. Authors of accepted manuscripts will be expected to assume obligation for payment of page charges, currently $\$ 75$ per page.

3. Author Information. Due to the double-blind review process used by the $J A A E$, authors should only provide their identity on the title page of the manuscript.

4. Manuscript Style/Format. Manuscripts must be on quality $8 \frac{1}{2}{ }^{\prime \prime} \times 11^{\prime \prime}$ paper with $1^{\prime \prime}$ margins, and be approximately 30 pages in length. Type only on one side of the paper, using left-margin justification only. Double-space all material throughout the manuscript, including abstract, acknowledgments, footnotes, and references. Use 12-point Times New Roman font style throughout. You must use either Word or WordPerfect for your manuscript, but we prefer Word.

5. Abstract. On a separate page, include an abstract not exceeding 100 words, followed by no more than eight key words or short phrases listed in alphabetical order (set the phrase Key Words: in italics and the key words themselves in roman).

6. JEL Classifications: Please provide the appropriate JEL classification codes for your manuscript following the Key Words. List these classification(s) in the following format: JEL Classifications: R51, R58, O21, O23, R11, R38

7. Footnotes. Number footnotes consecutively throughout the manuscript. Type the content of the footnotes on separate pages placed immediately after the main text. Footnotes should not be used solely for citations or directives to other literature. Reference citations should be incorporated into the main text or into the text of the footnotes.

8. References. Place all references cited in the text, alphabetized by author's last name (use initials for first names), on separate pages immediately after the footnotes.

9. Tables. Place each table on a separate page immediately after the references.

10. Figures. Place each figure, chart, or graph on a separate page immediately after the tables. We discourage the use of figures unless they are absolutely necessary. (Note: Figures of accepted manuscripts will be required to be set in PDF format in separate files.)

11. Mathematical Formulations. Use Arabic numbers enclosed in parentheses placed flush left on the first line of the equation. Number equations consecutively throughout the manuscript. Indent the equation after the equation number. Punctuate all mathematical material.

12. Copies. Please send four copies of your manuscript to:

John B. Penson, Jr., Editor, JAAE

Dept. of Agricultural Economics

Texas A\&M University; 2124 TAMU

525 Ireland St.

College Station, TX 77843-2124 


\section{Southern Agricultural Economics Association}

\section{Executive Committee}

President

Lester H. Myers, Virginia Tech University

President-Elect

Richard Kilmer, University of Florida

Past President

Steven C. Turner, University of Georgia

Director (1-Year Term)

Lois Schertz Willett, University of Florida

Director (2-Year Term)

Michele C. Marra, North Carolina State University

Director (3-Year Term)

Randall Little, Mississippi State University

Secretary-Treasurer

Kenneth W. Paxton and Lonnie R. Vandeveer, Louisiana State University

\section{Membership and Subscription}

Members of the SAEA consist of individuals and organizations with a professional interest in agricultural economics. Membership includes a subscription to the Journal of Agricultural and Applied Economics. Calendar-year membership dues are $\$ 30$ for regular memberships within North America (United States, Canada, Mexico, and the Caribbean), and $\$ 35$ for international memberships. Payment must be made in U.S. dollars.

The annual subscription rate for libraries and other institutions is $\$ 50$ within North America and $\$ 70$ outside North America. Single copies of current or back issues are available at $\$ 30$ within North America or $\$ 35$ outside North America. Payment must be made in U.S. dollars.

Address all subscription, membership, and change-of-address information to Kenneth W. Paxton and Lonnie R. Vandeveer, Secretary-Treasurer, SAEA, Department of Agricultural Economics and Agribusiness, 101 Ag. Admin., Louisiana State University, Baton Rouge, Louisiana 70803-5604. Telephone: (225) 578-2266; Fax: (225) 578 2716; Email: akpaxt@1su.edu or lvandeveer@agctr.lsu.edu; Internet URL: http:/www.saea.org/. 